\title{
LOS SOPORTES A LO LARGO DEL TIEMPO \\ Y SU INVESTIGACIÓN: LA TELEVISIÓN
}

\author{
Manuel Palacio \\ Universidad Carlos III
}

Me gustaría empezar estas páginas con una pregunta al lector o lectora; no la concibo como retórica ni baladí, sino medular para poder posicionarse en el título que nos reúne: Los soportes a lo largo del tiempo y su investigación. ¿Qué importancia damos individual y colectivamente a nuestro pasado televisivo, a la historia de la televisión? La respuesta es básica porque nos remite al uso que como colectividad posee el medio televisivo. Y huelga decir que las sociedades, según factores culturales y de otro tipo, asignan valores distintos a su relación con el pasado.

Busquemos un ejemplo iluminador en el cine. Aquellos que se dedican a la historia del cine se piensan como copartícipes de la elaboración de la historia general, como un ramal especializado de ésta (cierto es que es un sentimiento que las más de las veces no tiene reciprocidad por parte de los historiadores generales). Tienen aquellos, incluso, una asociación específica que va por los quince años de existencia: Asociación Española de Historiadores de Cine (http://apolo.uji.es/cine/index.php).

A su vez, las administraciones públicas desde que se crearon las primeras filmotecas, en la década de los treinta del siglo pasado, consideraron que el legado cinematográfico formaba parte del patrimonio nacional; tan es así que con la llegada de la España democrática la creación de filmotecas autonómicas ha sido una constante en todos los territorios. Véase la descripción de sus fines que hace la Filmoteca española: 
La colección de fondos fílmicos constituye el núcleo de la Filmoteca Española y su razón de ser. La Federación Internacional de Archivos Fílmicos (FIAF) otorga a estas instituciones el carácter de archivos históricos. Su peculiaridad estriba en que se trata, al mismo tiempo, de un archivo vivo, que se ocupa de recoger y preservar los documentos cinematográficos que se están produciendo actualmente, de garantizar su conservación y de facilitar su difusión con fines tanto de investigación como divulgativos. (Página web del Ministerio de Cultura: www.mcu.es)

Pues bien, en el ámbito de los estudios de televisión no existe en España un campo de historiadores de la televisión. A pesar de que en muchas universidades españolas de una u otra forma se imparten materias relacionadas con la historia de la televisión, lo cierto es que los académicos no han mostrado especial interés investigador sobre el pasado de la televisión. Las causas son diversas pero quizá la más llamativa es que los aspectos que conectan la televisión con la cultura de la comunidad son un objeto de estudio malo cuyo dominio está completamente deslegitimado en los foros académicos.

Desde otra perspectiva en nuestros lares institucionales tampoco se detecta preocupación alguna sobre el carácter patrimonial que poseen los archivos televisivos. En lo que respecta a las emisoras televisivas, en los más de los casos entienden el archivo como parte de sus actividades comerciales; en lo que se refiere al Estado hoy es el día que en España no existe ningún archivo público en el que se pueda visionar el pasado televisivo. El lastre para estudiarlo es tan pesado que en el conocido Llamado de París (Appel de Paris - Call from Paris), una convocatoria pública que se ha hecho desde la Federación Internacional de Archivos Televisivos (www.fiatifta.org), la presencia de firmas españolas es la más baja de los países de Europa occidental. Leámosla con el explícito objetivo de conseguir adhesiones.

Petición internacional para la preservación del patrimonio audiovisual mundial. Llamado de París. Este llamado tiene como finalidad: movilizar a todos los profesionales implicados en la preservación de nuestra herencia sonora y audio-visual; llamar 
la atención de todas las autoridades nacionales e internacionales en la situación crítica de nuestros acervos, peligrando la herencia mundial del audio-visual, especialmente en los países en vías de desarrollo; y proponer las medidas esenciales urgentes de preservación que hay que tomar para preservar los archivos. Cada uno tiene que sentirse implicado -profesionales de los medios, universitarios, archivistas, usuarios de los archivos, estudiantes, y todos los ciudadanos que se interesan por la preservación de la herencia audiovisual nacional. Por favor, enviar la petición a todos sus contactos para que todas las personas interesadas puedan agregar su firma, y facilitar la difusión de la petición en todos sus acontecimientos profesionales.

En suma, que el planteamiento clásico de la función de la historia como las operaciones de construir una memoria para crear una identidad común está lejos de ser cumplido por aquéllos que en España se dedican al estudio del largo tiempo de la televisión. Supongo que esa carencia se produce por muchos motivos, entre los que destaca el hecho de que voces que hablan sobre el pasado de la televisión no tienen un único centro normativo sobre el que articular los discursos y dar sentido a la lectura (tal como en el caso del cine suele ser el acercamiento estético a lo que algunos llegan a llamar séptimo arte). Este es verdaderamente el tema decisivo para comprender la investigación sobre la televisión. Veámoslo.

Es un lugar aceptado por los estudios sobre la televisión el considerar que ésta posee muchas dimensiones: económicas, tecnológicas, sociológicas, político-legislativas, estéticas, culturales, etc. Cada una de esas dimensiones han sido utilizadas para conatos de acercamientos históricos al pasado televisivo español en su uso de herramientas analíticas diversas y desde luego con cánones de interpretación diferenciados según las disciplinas. Verbigratia: la lectura del pasado televisivo basado en la economía, en los sistemas de producción de los programas o el fundamento económico de las modificaciones tecnológicas; la lectura socio política nos puede hablar de las modificaciones en el espacio público y en las ideologías generadas o reflejadas por la televisión (por ejemplo 
los cambios en la visión de la familia o de la mujer en los programas de ficción); la lectura político legislativa se ha revelado productiva para analizar determinados periodos, las instituciones que controlan la televisión o la evolución de algún género como el informativo; por último, la lectura estética permite centrarse en la historia de las formas estéticas y de la calidad televisiva.

Aun así, no se ha visto en la bibliografía española acercamientos que focalicen su atención en zonas iluminadas en otras latitudes. Por ejemplo, la mirada sobre las personas que realizan la televisión (directores, técnicos, interpretes) y con mayor calado el análisis de los públicos televisivos: el papel de la socialización, los perfiles de los telespectadores, el listado de los programas de éxito, entre otros. Una especie de historia social de la televisión. Tampoco están especialmente asentados en nuestros lares el estudio de los subpúblicos que como los teléfilos dan sentido a los clubs de internet y al intercambio de programas del pasado (cierto es que a lo largo del último año y quizás a rebufo de la consolidación del DVD como soporte de reproducción de imágenes, y base de las videotecas particulares, ha proliferado la comercialización de documentales y series de ficción del pasado -algunas por cierto más o menos míticas que nunca llegaron a verse en las cadenas españolas como la británica The Young Ones.

Y si lo dicho no fuera un obstáculo lo suficientemente elevado también los que nos dedicamos a la historia de la televisión nos encontramos con problemas metodológicos para poder centrar nuestro objeto de estudio. ¿Nos cobijamos en el árbol de la historia de los medios, como la radio e incluso el cine, o en la historia de la cultura de masas en lo que tiene la televisión como elemento central de socialización y configuración del espacio público? En otras palabras, ¿echamos mano de las herramientas analíticas provenientes de las ciencias humanas o de las ciencias sociales? No olvido, por supuesto, que los sociólogos en España no han mostrado (sorprendentemente) ningún interés en pensar científicamente la televisión. Personalmente, en mi Historia de la televisión en España intenté dar fe del sistema televisivo como glo- 
balidad, lo que me forzó a utilizar una metodología ecléctica, privilegiando en cada capítulo aquellos aspectos que daban sentido al periodo tratado.

La periodización del pasado para poder analizar y organizar el soporte televisivo a lo largo del tiempo no es un problema despreciable. Piénsese que por ejemplo en el cine son habituales las segmentaciones por décadas, además de otras que indican cambios tecnológicos (la llegada del sonoro), modificaciones legislativas (las diversas leyes de fomento a la cinematografía) u otras establecidas por cortes históricos (el cine de la transición); sin embargo en la televisión no se hallan resueltas las segmentaciones históricas.

En el caso de TVE y del conjunto de la televisión española con frecuencia se han utilizado criterios basados en motivos políticos en cierto sentido exógenos al propio desarrollo del medio: así encontraríamos la televisión en el franquismo, en la transición, el primer periodo socialista, y luego del PP... Excusado es decir que el problema es de tal magnitud que hay una parálisis en los estudios históricos.

Históricamente, en la televisión los dos registros temporales más habituales han hecho referencia a las cronologías lineales o al proceso evolutivo de los géneros. En la actualidad, debido a la proliferación de las ofertas televisivas ambos sistemas han quedado, de hecho, afectados y quizá por ello hace tiempo que no se publican libros con vocación histórica sobre la televisión. Quedan, eso si, las aproximaciones de base histórica al recorrido de algunas emisoras autonómicas (la catalana, la vasca, la gallega, la andaluza, etc.). Empero, no las hay a las cadenas privadas. Ahora, con motivo del cincuenta aniversario del comienzo de las emisiones regulares por TVE, se va a hacer un libro conmemorativo del evento.

Se me ocurren y propongo varias tipologías posibles y convencionales de «historias de la televisión». Y recuerdo que también es posible realizar historias en imágenes de la televisión porque la televisión más que otros medios de comunicación se 
historia a si misma en imágenes y en programas que de hecho constituyen el acervo colectivo de lo que la gente conoce como pasado televisivo.

- 1. Historia sociocultural de la televisión. Desde una primera perspectiva, la manera de conectar los programas televisivos con la experiencia social del consumo y con la realidad social. Y desde una segunda, la visión de la televisión como fuente de la historia. Se me ocurren algunos ejemplos notables: ialguien cree que se puede entender el cambio de costumbres que se produjo en el tiempo de la transición democrática sin tener presente Verano Azul, La Barraca o Los gozos y las sombras?

- 2. Historia económica de la televisión que aborde, entre otros aspectos, las fases de la organización industrial, los modos de producción, las variaciones en las tecnologías de producción y consumo (desde la llegada del color hasta el mando a distancia).

- 3. Historia de los programas, de las programaciones. Historia estética. El modo de representación y los estilos de realización. Por ejemplo, en este punto, pienso en los programas de referencia en la historia del medio. 